\title{
Domestic asbestos exposure, lung fibre burden, and pleural mesothelioma in a housewife
}

\author{
M HUNCHAREK,' J V CAPOTORTO, ${ }^{2}$ J MUSCAT $^{3}$ \\ From the Boston University School of Medicine, ${ }^{1}$ Boston, Massachusetts, Staten Island Hospital, ${ }^{2}$ Staten Island,
} New York, and Memorial Sloan-Kettering Cancer Center, ${ }^{3}$ New York, USA

Although the risk of mesothelioma associated with occupational exposure to asbestos is well documented, ${ }^{1}$ the risk posed by environmental and domestic exposure is uncertain. ${ }^{2}$ Epidemiological analyses of this problem is complicated by the lack of reliable estimates of the asbestos-mesothelioma dose response relation. ${ }^{3}$ We report here on a diffuse pleural mesothelioma in the wife of a shipyard machinist with quantitative evidence of substantial lung asbestos fibre burden from domestic contact. Although previous reports have documented an increased risk of asbestos related diseases among household contacts of asbestos industry workers, to our knowledge this is the first to provide data on actual lung fibre burden. This report suggests that such household contamination can result in "bystander" exposure levels similar to those found in the industrial setting.

\section{Case report}

A 76 year old woman (non-smoker) born in 1906 was well until the spring of 1982 when she developed right sided chest pain. In late November 1982 she was admitted to another hospital with rapid heart beat and complained of episodes of severe epigastric pain radiating to her chest. Physical examination at this time showed a right sided pleural effusion. Cope needle biopsy of the right parietal pleura showed atypical mesothelial proliferation and pleural fibrosis. Pleural cytology was benign. She was discharged in early December 1982. She had had a cholecystectomy in 1979 and a history of diverticulosis and congestive heart failure.

In January 1983 she was re-admitted to hospital complaining of pleuritic chest pain and shortness of breath. Chest $x$ ray examination showed pronounced re-accumulation of the pleural effusion. The patient subsequently underwent needle biopsy of the right parietal pleura followed by removal of $1000 \mathrm{cc}$ of

Accepted 23 May 1988 serous fluid. Biopsy showed a malignant neoplasm $\stackrel{\mathbb{D}}{3}$ consistent with malignant mesothelioma of the $+\vec{f}$ biphasic subtype.

In March 1983 a chest tube was placed and tetra- $\omega$ cycline was instilled which satisfactorily controlled the $\oplus$ effusion. She received no chemotherapy or any specific오 treatment for the disease. One month before death, $\rightarrow$ June 1983, her clinical state deteriorated with gradual weight loss, decreased appetite, and increasing weakness. The patient died from her malignant meso- $\overrightarrow{0}$ thelioma in early July 1983.

Necropsy showed a malignant mesothelioma affecting the right chest with extension to the mediastinum, pericardium, and left chest. No evidence of metastatic disease or other primary tumour was found.

The occupational history showed no direct苂 occupational exposure to asbestos. An extensive interview with the patient's husband established that $\overrightarrow{\overrightarrow{0}}$ he was employed for 34 years (1935-69) as a machinist 3 in a shipyard, where he dismantled boilers and other shipyard machinery throughout his employment. He. stated that his workclothes became "covered witho dust" and that his wife regularly laundered these $\exists$ clothes at home.

Before beginning employment as a machinist, he had worked as a merchant marine (1931-2), a rigger'so helper on bridge construction (1932-4), and on bridge construction assembling cranes for a constructions company. No exposure to asbestos was known to occur during this period (1931-4). He retired from hiso. job as a shipyard machinist in 1969 and no other occupational history was given.

This patient married her husband in 1931 at the age of 25 , after which she never worked outside the home Her occupational history before 1931 was not giveng Her only documented exposure to asbestos was by secondary exposure through laundering her husband's asbestos contaminated workclothes. At necropsy, the patient's left lung was removed for asbestos fibre analysis by an expert pathologist. The report of this, analysis was reviewed and the results are summarise in the table. 
Lung asbestos fibre content

\begin{tabular}{|c|c|c|}
\hline Fibre type & $\begin{array}{l}\text { No of fibres } / g \\
\text { wet lung tissue }\end{array}$ & $\begin{array}{l}\text { No of fibres } / g \\
\text { dry lung tissue }\end{array}$ \\
\hline $\begin{array}{l}\text { Chrysotile } \\
\text { Amosite and crocidolite } \\
\text { Tremolite, actinolite, } \\
\text { and anthophyllite }\end{array}$ & $\begin{array}{r}172 \times 10^{3} \\
59 \times 10^{3} \\
221 \times 10^{3}\end{array}$ & $\begin{array}{l}2.5 \times 10^{6} \\
0.8 \times 10^{6} \\
3.2 \times 10^{6}\end{array}$ \\
\hline
\end{tabular}

\section{Discussion}

Since the initial report of family contact asbestos associated mesothelioma by Newhouse and Thompson in $1965,{ }^{4}$ additional evidence has accumulated indicating that indirect exposure to asbestos in the home may be a serious health hazard..$^{5-7}$ In most instances asbestos fibres are carried home on worker's clothing and liberated on removal and during preparation for laundering. ${ }^{8}$

Interestingly, only one study has attempted to quantify the actual exposure to asbestos fibres in the homes of asbestos workers. ${ }^{8}$ Nicholson et al found that chrysotile asbestos concentrations in the air of the homes of 13 asbestos mine and mill employees ranged from 50 to over $2000 \mu \mathrm{g} / \mathrm{m}^{3}$. Samples from three neighbouring homes of non-miners ranged from 32 to $65 \mu \mathrm{g} / \mathrm{m}^{3}{ }^{8}$ Unfortunately, few quantitative data are available regarding actual respired dose of asbestos fibres by household contacts in such settings.

As seen in the table, the lung asbestos fibre content of this woman was similar to that seen in cases of mesothelioma associated with occupational exposure to asbestos.' Since lung fibre concentrations exceeding 1 million fibres per gram of dried tissue are associated with an increased risk of malignant mesothelioma, it appears that such household contact, as described above, may represent a considerable risk of mesothelioma.

Currently, the nature of the dose response relation for asbestos related mesothelioma is uncertain. Part of this uncertainty arises from the lack of accurate exposure data and information on fibre type. The data provided here indicate that secondary asbestos exposure in the home can be substantial, as reflected by the lung fibre burden outlined in the table. Such exposures should therefore not be assumed to be "light" exposures.

This case report therefore provides evidence that family members exposed to asbestos fibres brought home on the workclothes of asbestos industry workers may accumulate lung fibre burdens similar to those seen in the occupationally exposed individuals and this contamination may constitute a significant risk of mesothelioma.

This case was obtained from the files of the Canadian Tumor Reference Center with which MH was previously affiliated. We thank the Reference Center for help with this report.

Requests for reprints to: Michael Huncharek, MPH, Box 487, Boston University School of Medicine, 80 East Concord Street, Boston, Mass 02118.

\section{References}

1 Selikoff IJ, Lee DH. Asbestos and disease. New York: Academic Press, 1978.

2 Huncharek M. The epidemiology of pleural mesothelioma: current concepts and controversies. Cancer Invest (in press).

3 Peto J, Seidman H, Selikoff IJ. Mesothelioma mortality in asbestos workers: implication for models of carcinogenesis and risk assessment. Br J Cancer 1982;45:124-35.

4 Newhouse ML, Thompson $H$. Mesothelioma of pleura and peritoneum following exposure to asbestos in the London area. $\mathrm{Br} J$ Ind Med 1965;22:261-9.

5 Li FP, Lokich J, Lapey J, Neptune WB, Wilkins E. Familial mesothelioma after intense asbestos exposure at home. $J A M A$ 1978;240:467.

6 Vianna NJ, Polan AK. Non-occupational exposure to asbestos and malignant mesothelioma in females. Lancet 1978;ii:521-2.

7 Anderson HA, Lilis R, Daum SM, Fishbein AS, Selikoff IJ. Household contact asbestos neoplastic risk. Ann NY Acad Sci 1976;271:311-23.

8 Nicholson WJ, Rohl AN, Weismann I, Selikoff IJ. Environmental asbestos concentrations in the United States. IARC Sci Publ 1980;2:823-7.

9 Mowe G, Glyseth B, Hartveit F, Skaug V. Fiber concentration in lung tissue of patients with malignant mesothelioma: a case control study. Cancer 1985;56:1089-93. 